\title{
American Individualism and Masculinity? The Case of Nursing Homes
}

Rosa M. Pacheco Baldó

Department of English Studies, University of Alicante, Alicante, Spain

rosa.pacheco@ua.es

ORCID: https://orcid.org/0000-0003-2740-9693

Address: Universidad de Alicante. Dpto. Filología Inglesa. Ctra. San Vicente del Raspeig, Spain, 03690

Autobiographical note:

PhD Rosa M. Pacheco Baldó is a lecturer in the Department of English Studies at the University of Alicante. She is a Doctor in English Studies and she has an additional degree in Social and Cultural Anthropology. Thus, her preferred field of study is intercultural pragmatics, with a special interest in comparative linguistics and cultural issues. Her line of research is focused on how cultural differences reflect upon speakers' discourse, particularly in the field of social sciences. 


\section{American Individualism and Masculinity? The Case of Nursing Homes}

The aim of this article is to show that opposing cultural values can coexist in the same culture at a time. The United States is typically featured as a society representative of individualist and masculine cultural values. Nevertheless, the conditions given in some contexts collide head on with this view. The case that this article examines is one of these scenarios. The analysis of more than a hundred statements from fifteen nursing homes has shown that these centres try to convey messages compatible with tribal-group and feminine values. At a vulnerable time of life, as ageing is, owing to the need for assistance or to a desire to feel safe, what is attractive is knowing that one is going to be in a place of warmth. People seek for an environment of cooperation and care and not of competition and detachment. The discourse that these centres use to attract customers, opposes somehow the individualist and masculine values that are usually associated with the American culture. Therefore, this article discusses the importance of context and the communicative situation, which tilt the discourse used by the speakers even if it does not reflect the values traditionally assigned to their cultural group.

Key words

femininity, masculinity, individualism, tribal-group, context, nursing homes

\section{Introduction}

Research on cultural dimensions has received some criticism over the years due to the fact that not everyone likes to be classified within a uniform set of traits, as if their behaviour could be predictable and quantifiable. However, this is not as these studies are to be taken. The described values represent a trend at a national level and not an individual one, and therefore, it should be understood that not all members of a group 
are equal among themselves and that in the same group there are as many differentiations as individuals. Likewise, they must not be used to construct rigid stereotypes about societies, in the sense of beliefs and expectations shared by people about the characteristics that women and men should have within society (Mensa \& Bittner, 2020), as sometimes these stereotypes include false assumptions built over the years. As Bennett explains (2004), the measurements offered by Hofstede and similar authors like Hampden-Turner and Trompenaars are very useful for studying cultural differences at the national level, i.e. among countries. Also, studies like Bhaskaran and Sukumaran (2007) show that the influence of national culture on workers may be even bigger than the organizational culture of a company. An and Kim (2007) also highlight the value of Hofstede's empirical work, since when making his calculations, he used a sample of thousands of individuals consulted in more than seventy countries.

In this study, I have focused particularly on two dimensions, namely, individualism/collectivism and masculinity/femininity. On the one hand, the duality individualism/collectivism has been one of the most studied dimensions, if not the most, along with the dimension of power. It is commonly considered that the individualism/collectivism dimension refers to the relationship that each individual establishes with the rest of society, as regards the groups that are formed in society, the cohesion between the members, the ties that bind them, etc. (Hampden-Turner \& Trompenaars, 1998, 2000; Hofstede, 1991, Hofstede et al., 2010). These relationships or links can be very soft and fragile, as in the case of individualist societies, very strong and conditioning as in collectivist cultures, or intermediate, as in tribal cultures (Leaptrott, 1996). The term tribal was coined by Leaptrott (1996) to refer to cultural groups where both individualist and collectivist values can be found. Individuals in these societies have a preference for relationships within small groups, like work 
groups, extended family groups, etc., so that is why I will refer to these cultures as tribal-group ones.

On the other hand, the dimension of masculinity/femininity represents the deepest societal structure (Triandis \& Suh, 2002), and has also been frequently addressed by studies in pragmatics, applied linguistics and many other fields of studies. However, many people find a difficulty in understanding and accepting the values that this dimension measures. When Hofstede launched this dimension, it received harsh criticism, particularly by the countries that were categorized as masculine. The reason was that they felt undervalued and somehow annoyed because they seemed to be branded as insensitive and selfish. In his defence, Hofstede (1998) argued that, firstly, if differences in so many countries appeared it should be because there is really a reason underlying at an anthropological level, although not at a personal or psychological one (Hofstede, 1998). Secondly, he recommended those societies where the terms would not fit well, that other dualities could be taken, such as ego/social or assertive/nurturant, following the original idea of the authors who had inspired him, i.e. Inkeles and Levinson (1954). According to Hofstede (1998), what the masculinity/femininity dimension intends is on the one hand, to differentiate between those societies where there are major or minor differences in the roles that men and women assume. On the other hand, it also wants to distinguish between those societies where competitiveness, assertiveness and the attainment of personal achievements are regarded as something positive, as opposed to those societies where cooperation, the maintenance of harmony, care and empathy towards others as well as the complementarity of the sexes are an ideal (Hofstede, 1991). In other words, the dimension tries to differentiate between cultures with an orientation towards achieving and idealising the well-being of the ego, rather than society's welfare, or, quite the opposite. Hampden-Turner and Trompenaars 
$(1998,2000)$ also included some of these cultural traits in their analysis, though they grouped them under the name internal direction/outer direction, and they described the dimension as the preference for achievement of personal goals, as opposed to avoidance of conflict and search for cooperation.

Regarding the criticism received by these authors in terms of update and validity of their studies, as Dahl (2004) pointed out, and as we can see from the studies mentioned here, the models are continuously used in intercultural studies. Another evidence of this is that the dimensions identified by Hofstede and Hampden-Turner and Trompenaars are always included in the descriptions of cultural values that many advisory or consulting online firms use nowadays. They are dedicated to providing training and intercultural competencies both to companies and to individuals, as for example the pages http://wwwchangingminds.org, http://www2.thtconsulting.com/ managed by Hampden-Turner and Trompenaars or http://www.geerthofstede.com and https://www.hofstede-insights.com/ funded in 2017 from a merger between ITIM Culture and Management Consultancy and the Hofstede Centre.

Finally, concerning the studies on web pages in the field of health and welfare, I would like to mention Harrington et al.'s (2003) analysis about whether the data that the web pages of public and private nursing homes offer are what the consumer really needs. Also worthy of mention is the study of Stein de Sparvieri (2009) that analyses the discourse on associations of disabled people web pages. Llinas et al. (2008) analyse the differences between websites of American, British and Spanish hospitals, in terms of their design, and visual characteristics. However, these articles do not take into consideration the influence and relevance of cultural values. By contrast, Würtz's (2006) work does analyse the relationship between the design of the web pages and the cultural dimension of high-low context (Hall 1976), and she concludes that the cultural 
values described by Hall and Hofstede can be reflected upon the web design. As Hermeking (2006) maintains, cultural differences such as individualism, masculinity (Hosftede, 1991; 2010) or high-low context (Hall, 1976) are reflected not only in the website layout but also in the access and use that consumers make of web pages. In other words, cultural dimensions influence not only the design of web pages, but also the use that members of a society make of them and of internet in general (La Ferle et al., 2002; de Mooij, 2004; Mueller, 2004).

\section{Description of the Dimensions Used in this Paper}

The measurements that Hofstede et al. (2010) offer for the United States in the two dimensions analysed in this paper can be found in Table 1.

Table 1. Values obtained by Hofstede et al. (2010) for the United States in the dimensions included in this study.

\begin{tabular}{|c|c|}
\hline & The United States \\
\hline Individualism & 91 \\
\hline Masculinity & 62 \\
\hline
\end{tabular}

Firstly, as we mentioned above, the dimension of identity refers to the relationship of the individual with society. Hofstede's $(1991 ; 2001)$ and Hofstede et al.'s measurements (2010) appointed the United States a first place on the scale, with 91 points, followed by Australia with 90 and the United Kingdom with 89 points. Analysing Hofstede's postulates and applying them to the context that concerns us here, we could synthesise the main traits that an individualist culture can present in the following ones:

(1) Everybody must take care of themselves and their nuclear family. 
(2) The ideal of identity is based on the autonomy that the individual must have.

(3) Everyone has the right to have a private life without interferences imposed by the community.

(4) Decisions taken individually are highly valued.

(5) Rules and values underlying these must be applied to everyone equally.

(6) There is a strong emotional independence of the individual with respect to institutions and the system.

By contrast, let us see the features that characterise a tribal-group culture, a term coined by Leaptrott (1996) to refer to those cultures, such as for example the Spanish one, who are located at the intersection between individualism and collectivism. As tribal-group cultures are between the two extremes, we should avoid falling into generalizations that come near the two ends of the continuum individualism/collectivism.

(1) People should ensure their well-being, but also be concerned about their nuclear and extended family.

(2) The ideal of identity is the autonomy of the individual, but they should also be able to rely on institutions and the system.

(3) It is highly valued to belong to small circles of friendship, relationships, etc., although always maintaining the uniqueness of the person.

(4) Individual decisions are valued, but also those supported by the most immediate circle.

(5) Rules and values underlying these must be applied to everyone equally, although people know that this does not happen in practice. 
(6) There exists a relative emotional dependence of the individual with respect to institutions and the system.

Secondly, the dimension of masculinity/femininity has also been taken into account here. This dimension tells us what is the tendency of a national culture in terms of the values that are traditionally and typically attributed to men and women. For example, a country that scores high on the index of masculinity will have a culture where competition, success and achievement, are seen as something positive. By contrast, a feminine culture will be one where people will value cooperation, harmony and aid to those in need, to mention just but some features. The United States gets a score of 62 in Hofstede's ranking, so it is prone to show traits of masculinity.

In his specific study on this dimension, Hofstede (1998) explains that this is the only dimension that presented, in some countries, different results depending on the sex of the respondents. For example, in cultures that rated highly in masculinity, such as the Japanese, with 95 points, significant differences were found between the roles of men and women. In particular, men showed a preference for competition or the pursuit of individual success, while women tended more towards the pursuit of harmony, cooperation and concern for others. However, in general, all the participants in that country accepted competition as a positive thing in society. On the contrary, in cultures that rated low in masculinity, such as the Netherlands, with 14 points, there were hardly any differences between the roles of women and men, both in the field of work and at home. Furthermore, this culture showed a preference for the search for consensus, rather than competition. In other words, the reason why Hofstede adopted the masculinity/femininity name was because, despite measuring values and preferences at the national level, this dimension also showed differences depending on the sex of respondents, in countries that rated high in masculinity. 
In accordance with the context that concerns us, a cultural group inclined to masculinity would present the following features:

(1) Attainment of results and recognition by others is highly valued.

(2) People feel at ease within a framework of competition and challenges.

(3) Independent decision-making and assertiveness are valued.

(4) People who achieve success are highly esteemed.

On the other hand, for a culture closer to femininity we would find the following features:

(1) Friendly environments without tensions or conflicts are highly valued.

(2) Cooperation to achieve well-being in life is pursued.

(3) Service to others is an ideal.

(4) There is a greater awareness about those who are less fortunate.

\section{Individualism and Masculinity as Typical Cultural Traits in American Society}

The United States is commonly featured as an individualist country. Being located at the head of the rankings of this dimension (Hampden-Turner \& Trompenaars, 1998; Hofstede, 1991), it is used as a representative of individualist values, and therefore it is a point of comparison with other cultures. Kim et al. (2009), for example, explore the differences in South Korea concerning the design of web pages. In fact, the American culture has been compared on numerous occasions with Asian cultures (Kim et al., 1998; Lee et al., 2007; Singh et al., 2003; Würtz, 2006), since the latter tend to occupy the other end of the ranking of this dimension and others, as for example, the high/low context dimension (Hall, 1976). The United States has also been compared with Hispanic cultures (Estrada-Villalta \& Terpstra-Schwab, 2014; Kooyers, 2015; Singh \& 
Baack, 2004), for example, since we can usually find important differences too, in the sense that many of the latter are often collectivist or tribal-group cultures.

Likewise, the United States is usually described as a masculine culture since individualist cultures are generally related to masculinity and collectivist ones to femininity (Cienfuegos-Martínez et al., 2016; Lucker, 2002). The relationship that is established is due to the fact that in a masculine culture, where achievements, competition and recognition are appreciated, it is more logical to find individualist values that promote independence and the individual struggle for achieving the desired goals. On the contrary, a collectivist culture that idealises the welfare of the group over the individual is more prone to show feminine features like attention towards others, cooperation, maintenance of harmony, etc. (Gouveia et al., 2011; Hofstede, 1991; Lucker, 2002).

However, as Hall already defended, 'the meaning of a communication is always dependent upon the context' (Hall, 1976, p. 82), to the extent that, if the context so permits or requires, two extremes such as individualism and collectivism, can coexist in the same cultural group (Cienfuegos-Martínez et al., 2016; Correa et al., 2002; EstradaVillalta \& Terpstra-Schwab, 2014; Triandis et al., 1988). As we will see in this paper, in the case of nursing homes' web pages, the context changes the discourse regarding the typical individualist and masculine values of the United States. The reason is that in a context where vulnerable people are the protagonists, it is more logical and attractive to promote cooperation, care and attention to others — feminine and tribal-group valuesthan competitiveness and the individual struggle for achievements — masculine and individualist traits.

\section{Methodology}




\subsection{The Centres}

In this study, which was carried out from November 2018 to January 2019, I analysed a total of fifteen nursing homes in the area of Sacramento, a city of Mediterranean climate, with less than 500,000 inhabitants and with a per capita income of about $\$ 28.000$ (United States Census Bureau, 2018). I only took into account nursing homes in which a personal attention and service to customers is offered. In other words, I did not include residential communities, typical in the United States, where the elderly can live in independent housing but with all the services they need within reach. Obviously, in these cases the user demands to maintain independence and freedom of action. On the contrary, when adults are already at a stage of their life when they need care and attention from others, they cannot live independently and what they require is the support of others, and this is precisely what they can find in the analysed nursing homes.

The analysed centres were privately managed, as this is the general case in the United States $-69.3 \%$ according to CDC (2019)- although some of the centers offered themselves as intermediaries, in order to request any kind of help or subsidy to which the client might be entitled, according to the conditions required by the State. Unfortunately, virtually none of the centers published prices of their services, so these data could not be taken into account, if it had affected for the analysis at all. However, I do not consider this issue to be relevant since the cultural values studied here are considered at a national level and not taking other variables, such as the economic situation of the person, qualifications, social substrate, etc.

\subsection{The Corpus}


The messages conveyed by the nursing homes websites collected in this study are aimed at both the final users and their families. Normally, due to a better management of technology, the relatives initiate the search for the centre, and then they show their elder family member where he or she will live, reassuring them with the messages and images displayed on the websites. As these messages appeal to cultural values that are shared by the whole society, as in the case, they are very likely to be attractive for both the final users and their families.

A total of 116 statements were collected from the study of the websites, taking into account that some websites were more prolific than others when describing their services. Firstly, I set up a table that included the four cultural features studied here, namely, individualist values, tribal-group ones, masculinity values and femininity ones. Next, I read the home pages of the websites, and also the section usually called About us or Our Mission, that specifies the values and leitmotif of the centre. I read the statements and analysed the underlying messages that the centres try to convey in order to attract clients. Then, I wrote down in the table the statements and claims according to the cultural feature they related to. In order to obtain the relative frequencies for the four poles of cultural traits, I added the number of websites that had shown each of the cultural features under study. For example, statements that corresponded to individualist traits were found in thirteen out of fifteen centres, whereas in twelve of the fifteen centres, also tribal-group cultural features were found. Finally, a simple rule of three was applied to the relative frequencies data, thus obtaining the percentages. In the examples above, $86.6 \%$ of the websites conveyed messages compatible with individualist traits, and $80 \%$ of the websites conveyed tribal-group values.

\section{Results and Discussion}


In Table 2, we can see the percentages obtained from the analysed nursing homes, with respect to each of the groups of cultural traits included in the analysis.

Table 2. Percentages of traits found in the analysis

\begin{tabular}{|c|c|c|}
\hline & \multicolumn{2}{|c|}{ The United States } \\
\hline & Relative & Relative \\
& frequencies (fraction) & frequencies \\
(percentage) \\
\hline Individualist & $13 / 15$ & $86.6 \%$ \\
\hline traits & $12 / 15$ & $80 \%$ \\
\hline Tribal-group & & \\
\hline traits & $9 / 15$ & $60 \%$ \\
\hline Masculinity & & \\
\hline traits & $14 / 15$ & \\
\hline Femininity & & \\
\hline traits & & \\
\hline
\end{tabular}

In the first place, let us analyse the individualist and tribal-group features found on the websites. We must bear in mind that the United States is a benchmark for individualism, with 91 points on Hofstede's scale, therefore, what immediately draws our attention is the fact that in addition to finding individualist traits in $86.6 \%$ of the websites, something to be expected, also tribal-group features were found in $80 \%$ of the sites. Thus, on the one hand, as services aimed at people in an individualist culture, the American websites offer facilities that promise the individual to feel independent, autonomous, functional and with freedom of movement to the maximum extent 
possible, while maintaining their lifestyle and with their privacy and territory safe from intrusion. Some examples of these ideas can be found in these statements.

"Your loved one will have plenty of freedom to choose how they spend their day”. In https://www.brookdale.com/en/communities/brookdalegreenhaven.html?cid=yext

"But, you may ask, "what about privacy?" Your personal residence will give you all the privacy you desire". In https://www.srgseniorliving.com/

"They can maintain their privacy and independence while having options to socialize". In https://www.accsv.org/

"ACC will create an array of services to help older adults sustain their independence and lifestyle". In https://www.accsv.org/

"At Campus Commons, we celebrate the individual". In https://www.raystoneseniors.com/senior-living/ca/sacramento/campus-commonssenior-living/

In addition, the websites strive to ensure customers that they will be treated individually, meeting the specific needs of each one and as if they were in their own home.

"Our activities program serves to meet the individual needs of each resident." In https://saylorlanehealthcare.com/

"Ridge Assisted Living provides the best of individual care, while benefiting from a supportive loving lifestyle, companionship and activity". In http://www.ridgeassisted-living.com/ 
"You will know you are walking into your home". In http://www.ridgeassistedliving.com/

"Ray Stone Senior Living communities are founded on the premise that each individual's life experience is important and deserves to be celebrated". In https://www.raystoneseniors.com/senior-living/ca/sacramento/campus-commonssenior-living/

However, on the other hand, as much as twelve of the fifteen analysed websites $-80 \%-$ also showed tribal-group features. The reason for this lies in the present context, i.e., nobody wants to feel alone at a time of vulnerability as old age is, and nobody wants that their family member, if it is the case, feels abandoned. On the contrary, the idea that the centres want to convey is that the family member who is going to stay there will not be or feel alone and that they will not lose contact with their nearest ones.

"We give your loved one comfort and specialized care". In http://mckinley-parkcarecenter.com/

"Families are welcome to participate with their loved ones". In https://saylorlane-healthcare.com/

"We also pride ourselves in our communications with families, doctors and other medical support personnel”. In https://www.crmscommunities.com/senior_living/Sacramento_CA/zip_95827/claremont_retirement_management_services 18953

"You want to be certain that a senior living community will treat your loved one with the love and respect they deserve". In https://www.brookdale.com/en/communities-/brookdalegreenhaven.html?cid=yext 
"Your loved one is somebody special who deserves the very best and who will be treated with the utmost respect and dignity". In https://windsor-sacramento.com/

As we can see, some centres even stand as a replacement of the extended family or as a necessary agent of social and family change, in this context of personal need.

"At Covenant Care, we engage and empower our patients and their families at all stages of care". In http://www.covenantcare.com/

"Your neighbourhood extended family". In https://www.crmscommunities.com/senior_living/Sacramento_CA/zip_95827/claremont_retirement_management_ser vices/8953

"We invite you to see why $100 \%$ of our family members would recommend us". In https://www.carltonseniorliving.com/location/sacramento/

"We are committed to meeting the needs of our patients, families and communities. We strive to serve as extended family, all united in a circle of care". In http://www.covenantcare.com/

"We consider everyone as family and, like family, we care and support them. Our goal is for each member of the Ridge family to be happy and comfortable in their new home". In http://www.ridgeassistedliving.com/

As Han and Shavitt (1994) point out, in tribal-group and collectivist cultures, family ties are of vital importance. In other words, a tribal-group culture does not celebrate the complete independence of the individual, but people also like to be viewed as a valuable asset of society. The individual does not want to be considered as an indistinguishable 
element within a group, nor outside the group, but as a valuable and unique item within the group.

These data lead us to conclude what other studies defend (Cienfuegos-Martínez et al., 2016; Correa et al., 2002; Estrada-Villalta \& Terpstra-Schwab, 2014; Triandis et al., 1988), i.e., opposing cultural traits like individualist ones, and in this case tribalgroup ones can coexist in the same culture, if the context so requires.

Another feature that has also been found on the websites and which is identified as a trait of tribal-group cultures is the fact that they want to convey a feeling of togetherness and emotional affiliation among the workers of the centre. It is an ideal in tribal-group cultures that the company cares for the welfare of its workers, so that there is cohesion in the group and cooperation between members is encouraged (Arrindell et al., 1997).

“... build a team spirit among staff”. In http://www.universitypostacuterehab.com/

"Our teams work together with a great sense of camaraderie and respect for each other and our residents". In http://www.carefreeseniors.com/

“Carlton's employees are our most valuable assets". In https://www.carltonseniorliving.com/location/sacramento/

In the second place, the other cultural dimension studied herein, masculinity/femininity, was the one that brought the most surprising results, since, despite being the United States located in the upper middle part of Hofstede's scale, with 61 points of masculinity, as many as $93.3 \%$ of the websites showed typical features of femininity. It is commonly understood that a feminine culture enhances values such as cooperation, 
care and concern for others, as well as quality of life and interpersonal harmony (Arrindell et al., 1997). The United States is normally described as a masculine culture, where competition and attainment of results are of great importance in the vast majority of contexts (Hampden-Turner \& Trompenaars, 1998; Hofstede, 1991; Kessler et al., 2005). Hampden-Turner and Trompenaars describe it as an internal-direction culture as people express themselves openly and manage conflict constructively. That said, in this study I defend that the context is the cornerstone of every communicative act, since it limits and conditions the use of language (Schiffrin, 1991) and it also influences the cultural values that this language calls on. In a field such as the homes for elderly people, it is obvious that care, respect and emotional support towards others will be values to be highlighted, in order to instil peace of mind and security to users and their families. Therefore, the language used on these websites seeks the complicity with the reader and also a feeling of mutual affection between the receiver and the sender, so common in this means of communication (Yus, 2010). Some examples of this can be found in the following statements:

"ACC is respectful and sensitive in our relationships with our clients, donors, partners, residents, staff, volunteers and all within the community we serve". In https://www.accsv.org/

“... to provide compassionate care... creating a comfortable and nurturing atmosphere". In http://www.universitypostacuterehab.com/

“... to provide person-centered care with a loving touch. This is accomplished by having attentive and caring staff assembled”. In https://windsor-sacramento.com/

"We understand the importance of creating a comfortable and nurturing atmosphere". In http://mckinleyparkcarecenter.com/ 
"Dignity, health and happiness are key". In http://www.carefreeseniors.com/

"Step inside and see, it is full of warmth and comfort. It really is a great place to call home”. In https://www.srgseniorliving.com/

“... a team that is committed to Love, Honor and provide for our residents our communities are designed to provide a rich environment where being valued, respected and loved is a natural daily occurrence". In https://www.carltonseniorliving.com/location/sacramento/

"Each and every employee makes these following Commitments when they start and consistently throughout their time with us: Love - Act with Empathy, Compassion, and Understanding. Honor - Demonstrate Value and Respect to our seniors and their families. Provide - Display Exceptional Service, Enthusiasm and Integrity creating a safe and pristine environment". In https://www.carltonseniorliving.com/location/sacramento/

"Our staff is committed to treating each resident with dignity and respect while meeting their care needs on a long-term basis". In https://saylorlanehealthcare.com/

As we can see in the examples taken from the webs, the centres praise feminine traits such as concern for people, empathy, dignity of the human being, respect for the individual, etc. Thus, feminine cultural traits such as concern for others or social justice (Gouveia et al., 2011; Hofstede, 1991; Lucker, 2002) are highly valued in this context, despite being a group prone to masculinity, such as the American culture is usually featured.

Furthermore, as shown in Table 2, $60 \%$ of the websites also exhibited traits of masculinity in the descriptions of their services. The feature of masculinity that was found on these websites was the fact that they claimed to be the leader in some of the 
services they offer and, above all, they mentioned the prizes and awards they have achieved so far. Some examples would be the following claims:

"We are a Five Star Rated Facility for Registered Nurse Staffing”. In http://mckinley-parkcarecenter.com/

"State-of-the-art technology. Five-Star ratings. Our dedication to providing the highest quality care in the safest, most comfortable environment sets us apart". In http://www.covenantcare.com/

“Two Best of Seniors Living awards in 2016 and 2017”. In https://www.raystone-seniors.com/seniorliving/ca/sacramento/campus-commonssenior-living/

"Each one of our eligible retirement communities that has been CARF accredited has been awarded the maximum three-year accreditation. In fact, SRG is the only owner/operator of senior communities in the nation to receive such an honor". In https://www.srgsenior-living.com/

"Today, Carlton is one of Northern California's most successful senior living providers, winning national awards for its resident care, health and fitness and staffdevelopment programs". In https:/www.carltonseniorliving.com/location/-sacramento/ "Eskaton is pleased to announce it has received the "Caring Super Star of 2019" for service excellence in senior living. We encourage families to visit our competitors, observe resident and staff interactions, talk with other family members, and make the most informed choice possible". In https://www.eskaton.org/affordable-housing.html

This shows a preference for competition as well as honorary and material rewards (Páez \& Fernández, 2005). The reason for this is that, in masculine cultures, ambition and 
competitiveness are seen as something sound and healthy since it is believed that they promote the improvement of the service, which ultimately benefits the user.

\section{Conclusions and Final Remarks}

Three reflections can be drawn from this analysis. First, the cultural traits that are assigned to a group should always be considered as features at a national level and not at an individual one, with the variations that this implies (Bennet, 2004; Bhaskaran \& Sukumaran, 2007; Hofstede, 1998). Thus, measurements offered by Hofstede, Hampden-Turner and Trompenaars and other authors should be taken as generalizations of cultural groups. In other words, if we reach these generalizations it is because there is a reason at an anthropological level, but this should not lead us to rigid stereotypes applicable to all individuals in a society in all contexts, or even to caricatures of its members.

Secondly, the importance of context is crucial in every communicative act (Hall, 1976; Schiffrin, 1991). As we have seen, the cultural values required by a given context will prevail over those commonly assigned to that group. It is not the same a context where participants know and trust each other, as a context where the relationship among individuals is weak and unstable. In this study, in a context where attention and care to others are something positive, it would not have sense to speak of the competitive fight for resources that individuals are entitled to take in life.

Therefore, this leads us to the third conclusion, which is that opposing cultural values can coexist in the same cultural group, if the context so permits (CienfuegosMartínez et al., 2016; Correa et al., 2002; Estrada-Villalta \& Terpstra-Schwab, 2014; Triandis et al., 1988). In other words, just as a single individual can show opposite features in different contexts, the same can apply to an entire cultural group. In this 
case, the analysed websites enhance both the value of independence of the individual, and the benefits of being in a group where members take care of each other and, although they are really strangers, they are portrayed as a team, a community and even the very family. In other words, although the United States is a cultural group prone to masculinity and individualism, again, pushed by the context, the nursing homes websites feature a feminine and tribal-group discourse based on cooperation and harmony among people.

\section{References}

An, D. \& Kim, S. (2007). Relating Hofstede's masculinity dimension to gender role portrayals in advertising: A cross-cultural comparison of web advertisements. International Marketing Review, 24(2), 181-207.

Arrindell, W.A., Hatzichristou, Ch., Wensink, J., Rosenberg, E., van Twillert, B., Stedema, J. \& Meijer, D. (1997). Dimensions of national culture as predictors of cross-national differences in subjective well-being. Personality and Individual Differences, 23, 37-53.

Bhaskaran, S. \& Sukumaran, N. (2007). National culture, business culture and management practices: Consequential relationship? Cross Culture Management: An International Journal, 14(7), 54-76.

Bennett, J. M. (2004). Developing intercultural sensitivity: An integrative approach to global and domestic diversity. In D. Landis, J. M Bennett \& J. Bennett (Eds.), Handbook of Intercultural Training (pp. 147-175). Thousand Oaks: Sage.

CDC Centre for Disease Control and Prevention. National Center for Health Statistics, February 2019. Long-term Care Providers and Services Users in the United States, 2015-2016. https://www.cdc.gov/nchs/fastats/nursing-home-care.htm 
Cienfuegos-Martínez, Y.I., Saldívar-Garduño A., Díaz-Loving, R. \& Avalos-Montoya, A. D. (2016). Individualismo y colectivismo: caracterización y diferencias entre dos localidades mexicanas. Acta de Investigación Psicológica, 6, 2534-2543.

Correa, F., Contreras, C., Ramírez, A. \& López, E. (2002). Dimensiones del individualismo-colectivismo en México: un estudio exploratorio. La psicología social en México, 9, 553-559.

Dahl, S. (2004). Intercultural research: The current state of knowledge. London: Middlesex University.

Estrada-Villalta, S. \& Terpstra-Schwab, N. (2014). La complejidad de la variación transcultural: valores en Guatemala y Estados Unidos. Revista Interamericana de Psicología / Interamerican Journal of Psychology, 48(2), 152-165.

Gouveia, V., Milfont, T., Martínez, M.C. \& Paterna, C. (2011). Individualismcollectivism as predictors of prejudice toward Gypsies in Spain. Revista Interamericana de Psicología, 45(2), 223-234.

Hall, E.T. (1976). Beyond culture. New York: Doubleday.

Hampden-Turner, Ch. \& Trompenaars, F. (1998). Riding the waves of culture. New York: McGraw-Hill.

Hampden-Turner, Ch. \& Trompenaars, F. (2000). Building cross-cultural competence. Great Britain: Wiley.

Han, S.P. \& Shavitt, S. (1994). Persuasion and culture: advertising appeals in individualistic and collectivistic societies. Journal of Experimental Social Psychology, 30, 8-18.

Harrington, C., Collier, E., O’Meara, J., Kitchener, M., Payne Simon, L. \& Schenelle, J. (2003). Federal and state nursing facilities websites: Just what the consumer needs? American Journal of Medical Quality, 18, 21-37. 
Hermeking, M. (2006). Culture and internet consumption: Contributions from crosscultural marketing and advertising research. Journal of Computer-Mediated Communication, 11, 192-216.

Hofstede, G. (1991). Cultures and organizations: Software of the mind. London: McGraw-Hill.

Hofstede, G. (1998). Masculinity and femininity. The taboo dimension of national cultures. Thousand Oaks: Sage.

Hofstede, G. (2001) Culture's consequences: Comparing values, behaviors, institutions, and organizations across nations (2nd ed.). Thousand Oaks, CA: Sage.

Hofstede, G., Hofstede, G. J. \& Minkov, M. (2010). Cultures and organizations: Software of the mind ( $3^{\text {rd }}$ ed.). London: McGraw-Hill.

Inkeles, A., \& Levinson, D. J. (1954) National character: The study of modal personality and sociocultural systems. In G. Lindzey (Ed.) The Handbook of Social Psychology (pp. 977-1020). Reading, Mass.: Addison-Wesley.

Kessler, R., Chiu W., Demler, O. \& Walters, E. (2005). Prevalence, severity, and comorbidity of twelve-month DSM-IV disorders in the National Comorbidity Survey Replication (NCSR). Archives of General Psychiatry, 62(6), 617-27.

Kim, D., Pan, Y. \& Park, H. S. (1998). High- versus low-context culture: A comparison of Chinese, Korean, and American cultures. Psychology \& Marketing, 15(6), 507521.

Kim, H., Coyle, J.R. \& Gould, S.J. (2009). Collectivist and individualist influences on website design in South Korea and the U.S.: A cross-cultural content analysis. Journal of Computer-Mediated Communication, 14, 581-601. 
Kooyers, J. (2015). The United States and Spain: A comparison of cultural values and behaviors and their implications for the multi-cultural workplace. Honors Projects. 399. http://scholarworks.gvsu.edu/honorsprojects/399

La Ferle, C., Edwards, S. M. \& Yutaka, M. (2002). Internet diffusion in Japan: Cultural considerations. Journal of Advertising Research, 42(2), 65-79.

Leaptrott, N. (1996). Rules of the game: Global business protocol. Cincinnati, Ohio: Thomson Executive Press.

Lee, M. L., Geistfeld, L. V. \& Stoel, L. (2007). Cultural differences between Korean and American apparel web sites. Journal of Fashion Marketing and Management, 11(4), $511-528$.

Llinas, G., Rodriguez-Iñesta, D., Mira, J. J., Lorenzo, S. \& Aibar, C. (2008). A comparison of websites from Spanish, American and British Hospitals. Methods of Information in Medicine, 47(2), 124-130.

Lucker, G. (2002). La cultura y la psicología social. In C. Kimble, E. Hirt, R. DíazLoving, H. Hosh, G. Lucker \& M. Zárate (Eds.), Psicología Social de las Américas (pp.507-531). México: Prentice Hall.

de Mooij, M. K. (2004). Consumer behavior and culture: Consequences for global marketing and advertising. Thousand Oaks: Sage.

Mensa, M. \& Bittner, V. (2020). Portraits of women: Mexican and Chilean stereotypes in digital advertising. Communication \& Society, 33(1), 63-78. https://doi.org/10.15581/003.33.1.63-78

Mueller, B. (2004). Dynamics of international advertising: Theoretical and practical perspectives. New York: Peter Lang. 
Páez, D. \& Fernández I. (2005). Masculinidad-feminidad como dimensión cultural y del autoconcepto. In D. Páez, I. Fernández, S. Ubillos \& E. Zubieta (Eds.), Psicología Social Cultura y Educación (pp. 195-207). Madrid: Pearson.

Schiffrin, D. (1991). El análisis de la conversación. Panorama de la Lingüística moderna de la Universidad de Cambridge, vol. IV: El lenguaje: contexto sociocultural (pp. 299-323). Madrid: Visor.

Singh, N., Zhao, H. \& Hu, X. (2003). Cultural adaptation on the web: a study of American companies' domestic and Chinese web sites. Journal of Global Information Management, 11(3), 63-81.

Singh, N. \& Baack, W.D. (2004). Studying cultural values on the web: a cross-cultural study of U.S. and Mexican web sites. Journal of Computer-Mediated Communication, 9(4).

Singh, N., \& Baack, D. W. (2004). Web site adaptation: A cross-cultural comparison of U.S. and Mexican web sites. Journal of Computer-Mediated Communication, 9. http://jcmc.indiana.edu/vo19/issue4/singh_baack.htmlStein de

Stein de Sparvieri, E. (2009). Muestra de una investigación sobre análisis del discurso de páginas web de asociaciones de discapacidad de distintos países con metodología ADL. Subjetividad y Procesos Cognitivos, 13(2), 198-214. http://dspace.uces.edu.ar:8180/xmlui/handle/123456789/939

Triandis, H.C., Bontempo, R., Villareal, M.J., Asai, M. \& Lucca, N. (1988). Individualism and collectivism: Cross-cultural perspectives on self-in-group. Journal of Personality and Social Psychology, 54, 323-338.

Triandis, H. C. \& Suh, E. M. (2002). Cultural influences on personality. Annual Review of Psychology, 53(1), 133-160. 
United States Census Bureau. (2018). Quick Facts: Sacramento City, California, United States. https://www.census.gov/quickfacts/fact/table/sacramentocitycalifornia, US/PST045218

Würt, E. (2006). Intercultural communication on web sites: A Cross-cultural analysis of web sites from high-context cultures and low-context cultures. Journal of ComputerMediated Communication, 11, 274-299.

Yus, F. (2010). Ciberpragmática 2.0. Barcelona: Ariel. 